JOURNAL OF SECURITY AND SUSTAINABILITY ISSUES

ISSN 2029-7017 print/ISSN 2029-7025 online

2021 Volume 11

https://doi.org/10.47459/jssi.2021.11.23

\title{
COPING STYLES, DEFENCE MECHANISMS AND TIME PERSPECTIVES IN PATIENTS REPRESENTING TYPE I AND TYPE II ALCOHOL DEPENDENCE ACCORDING TO LESCH TYPOLOGY
}

\author{
Katarzyna Iwanicka \\ Academy of Justice, 50 Wiśniowa Street, 02-520 Warsaw, Poland \\ E-mail address: katarzyna.iwanicka@swws.edu.pl
}

Received 15 October 2020; accepted 10 April 2021; published 30 June 2021

\begin{abstract}
The present article analyses the relationship between coping styles, defence mechanisms and time perspectives in subjects representing type I and II alcohol dependence according to the classification developed by Lesch. The results showed that among people belonging to type I addiction according to Lesch, a higher intensity of coping style focused on emotions is associated with a higher level of immature defence mechanisms, in particular denial and devaluation. A higher intensity of task-focused coping style in type I alcohol dependent individuals according to Lesch is accompanied by the use of mature defence mechanisms, such as humour and anticipation. In the group of people with type II alcoholism according to Lesch, focusing on past positive events is associated with an increased use of avoidant coping style, as well as its two subscales - engaging in substitute activities and seeking social contacts.
\end{abstract}

Keywords: alcohol addiction; Lesch's typology of addiction; defence mechanisms, security; time perspectives

Reference to this paper should be made as follows: Iwanicka, K. 2021. Coping styles, defence mechanisms and time perspectives in patients representing type I and type II alcohol dependence according to Lesch typology. Journal of Security and Sustainability Issues, 11, 265-276. https://doi.org/10.47459/jssi.2021.11.23

JEL Classifications: I12

Additional disciplines: psychology, psychotherapy, medicine

\section{Introduction}

Alcohol dependence syndrome is an important social problem not only owing to how it develops and its medical sign, but also because of the personal and health consequences for the addicts themselves. According to data collected as part of the EZOP survey, alcohol dependence was confirmed at some point during life in $2.2 \%$ of adult Poles, while alcohol abuse concerned as many as $10.9 \%$ of adults in Poland (Kiejna et al. 2015). Excessive alcohol consumption is responsible for $7.4 \%$ of all disabilities and premature deaths across the European Union, while 5.9 million children live in families with alcohol problems (Anderson and Baumberg 2006).

In the light of the above data, it seems vital to present a complete therapeutic offer for alcohol dependent individuals, as this disorder affects the functioning of the entire family system (Cierpiałowska and Ziarko 2012). It is worth remembering, however, that alcohol dependent people do not constitute a homogenous group, as demonstrated by studies dedicated to the typology of alcohol dependence syndrome (Babor 1996; Cloninger 1987; Pombo and Lesch 2009; Woronowicz 2009). The typology of alcoholism by Otto Lesch, which is pivotal for this article, is a valuable proposal allowing for profiling pharmacological treatment as well as psychological therapy to the needs of particular groups of patients (Lesch et al. 1998; Kogoj et al. 2010). This typology was based on biochemical, physiological and clinical data related to the patients' functioning (Lesch et al. 1998 5). 
In addition, it should be noted that the study of diagnosis and treatment effectiveness was carried out over a period of 5 years of observation, resulting in the identification of four types of alcohol dependence, due to the different reasons for using alcohol, different presentation of the abstinence syndrome and the recommended forms of treatment. The research tool to measure the type of alcohol dependence according to Lesch has been translated into 12 languages and adopted for clinical research in a number of countries (Jakovljevic et al. 2014). According to its assumptions, there are four types of alcohol dependent patients. The first of the discussed types, the so-called "allergy model", concerns people whose social drinking progresses into compulsive drinking, and whose craving for alcohol is increasingly difficult to control. Abstinence symptoms appear at an early stage with alcohol being consumed to prevent their onset. Family history of alcohol abuse is often found in these patients. The second type was termed an anxiety type (term such as "problem solving" is also in use) and is found in people who consume alcohol owing to its anxiolytic effect. Under the influence of alcohol, their behaviour may change, from withdrawn and submissive to aggressive. In the case of this type, there are no severe somatic complications of alcohol dependence, nor do the symptoms of abstinence occur. The third type is called "alcohol as an antidepressant model". It concerns people who, apart from symptoms of alcohol dependence, exhibit symptoms of mental disorders and diseases, in particular affective disorders. Drinking alcohol is therefore linked to the periodic occurrence of affective disorders, with periods of abstinence occurring in between; alcohol is consumed in order to enhance mood and improve sleep. Somatic symptoms of abstinence syndrome tend to be mild. The fourth, and last, of the discussed types of alcohol dependence, according to Lesch, is called "conditioning model". People with this type are characterised by primary damage to the central nervous system that developed before the age of 14. The history often includes perinatal trauma or serious somatic illness during childhood and adolescence. These patients also suffer from grand mal seizures at times other than those associated with the abstinence syndrome.

Very few studies have addressed the issue of differences in personality variables in patients belonging to different types of alcohol dependence according to Lesch. The available studies show that alcohol dependent individuals presenting type I according to Lesch, as compared to those with type II, are characterised by increased impulsivity and need to seek novelty (Samochowiec et al. 2011). An analysis of the psychological functioning of people with different types of alcohol dependence according to Lesch, and a search for differences in this area, would make it possible to improve the therapeutic offer, as well as provide important guidance for clinicians.

\section{Time perspectives and alcohol dependence}

In the case of alcohol dependent patients an extremely important issue seems to be how they approach time. A holistic approach to the issue of time perception perspectives was presented in the book entitled "The Time Paradox" by Philip Zimbardo and John Boyd (Zimbardo and Boyd 2012). The authors define time perception perspectives as "the personal attitude, often unconscious, that each of us adopts towards time. It is also the process by which the relentless flow of life is broken down into temporal categories, helping to give our lives order, coherence and meaning" (ibid., p. 50). According to the authors, not only individuals, but also entire societies present specific temporal perspectives. Thus, time perspective consists of a time horizon (oriented towards the future, past or present) and an emotional valuation (positive or negative). In a questionnaire he created on the perception of time, Zimbardo distinguished the following perspectives:

- past-negative,

- future-positive,

- present-fatalistic,

- present-hedonistic,

- future-oriented.

The past-negative perspective on time may be the result of real-life traumatic experiences or result from ongoing negative reconstruction, alternatively it may be a combination of both (Zimbardo and Boyd 1999). Individuals scoring high on the past-negative scale are characterised by less impulse control, greater propensity to gamble and weaker ego boundaries compared to those scoring low. Additionally, in terms of daily functioning, they engage in less physical exercise and have lower energy levels. They are also more likely to experience 
ruminations, reminiscing about painful and difficult past experiences. Individuals scoring high on the pastpositive scale concentrate on the past events they have experienced, yet they recall more good things than bad from their memory. Such reminiscences give them pleasure, and often evoke the feeling of nostalgia about past times. They are characterised by a strong attachment to tradition and family values. A positive assessment of the past also shapes the conviction that the world is favourable and orderly (Zawadzka and Byrczek 2012). The present fatalistic time perspective is connected with the feeling of lack of influence over one's life and the conviction that the shape of existence is determined by fate or force majeure. People presenting such a perspective are in a way "trapped in the present", living only today, assuming that it is not worth planning the future, as it does not really depend on them anyway. People who score high on this scale have a low sense of self-efficacy and are often characterised by learned helplessness - a term introduced by Martin Selingman, which refers to the fixed belief that there is no connection between one's actions and their results. As research has shown (ibid.), this time perspective can be associated with reduced openness and higher levels of aggression. This can be explained by the fact that people who experience a lack of control over their lives are more likely to shift the responsibility for their bad situation onto others, engaging in anti-social and anti-other behaviours.

People with a hedonistic present time perspective actively seek and maximise pleasure. They have difficulty deferring gratification, and exhibit a high need for stimulation. Characteristic for them is that they are able to keep their attention on an activity or relationship until they feel bored, then they tend to swiftly change the object of interest. People with higher scores on this scale are less emotionally stable and have a poorer impulse control than those with low scores. Studies by Zawadzka and Byrczek (2012) have shown, however, that the ease of risk-taking in present hedonists may be conducive to interpreting potentially dangerous events as less threatening and to better adaptation to chronic illness, as was the case with chronic dialysis patients. Qualities such as weaker ego boundaries and a tendency to prefer inconsistency in life may indicate a greater susceptibility to compulsive behaviour, such as addictions. As Zimbardo succinctly summarised: "drinking alcohol and taking drugs are particularly dangerous for present hedonists because these substances cause a dulling of the higher thought centres in the brain, leading to a heightened orientation on the present" (Zimbardo and Boyd 2012, p. 177). Thus, a vicious circle is at work here: in the case of present hedonists, drinking alcohol reinforces the presented time perspective, which leads to even greater consumption of psychoactive substances and, consequently, hinders the development of a constructive vision of one's own future. It should be added that the authors also distinguished a third present time perspective - holistic, meaning "the absolute present", which combines elements of the future and the past and has its roots in the Buddhist tradition and the idea of mindfulness and being "here and now".

A future-oriented perspective on time is associated with creating representations of future states and organising one's activities around life plans and goals. Postponing gratification in order to obtain an even greater reward is a quality that characterises people with high scores on this scale. Factors favouring the development of a future-oriented time perspective include having a job, living in a stable family, obtaining education, and having future-oriented role models. Future-oriented individuals are more interested in the consequences of their actions, they manage themselves better in time, using schedules and calendars. They spend less time reflecting on past events, and achieve lower levels of depressive symptoms. Such people are more attentive to health and well-being, consume less alcohol, are more likely to eat healthy food and seek preventive health check-ups. It is worth noting that they present a more constructive strategy for coping with stress, being action- rather than emotion-oriented.

Research has shown that there is a correlation between engaging in risky behaviours, such as casual sexual contact, driving too fast or using psychoactive substances, and individuals' time perspectives, in this case a positive correlation for present time perspective and a negative correlation for future time perspective (Keough et al. 1999). It has also been demonstrated that students with a past time perspective not only consume more alcohol, but also reach for it more often than those with a more future oriented perspective (ibid.). It is worth noting that people with a present time perspective more readily disavow the distant consequences of alcohol abuse, such as, for example, feeling bad the next day, or those even more postponed in time, such as job loss, breakdown of family ties or deterioration in health. As shown in a study by Petry et al. (1998), heroin addicts scored sig- 
nificantly higher on the scales of present hedonism and fatalism, and lower on the scale of future-oriented time perspective than the control group. This may be related to the fact that addicts prefer the immediate reward of relief and release of tension that comes with the use of substances, rather than the deferred gratification of professional success or satisfying relationships.

Chodkiewicz and Nowakowska (2010) have demonstrated that among alcohol dependent individuals beginning withdrawal therapy, the dominant time perspectives were those directed towards the past and the present in the context of hedonism. They also found that the stronger the concentration on the present in the fatalistic aspect, the greater the patients' sense of threat from current problems and their belief that they have no influence on their life and what will happen in it. Patients who focused on the past scored higher on the harm scale, which may reflect their greater passivity and extrinsic motivation for treatment. Further Polish studies have shown that patients entering treatment for the first time, more often than those undergoing treatment for the next time, present a future-oriented time perspective (Chodkiewicz and Nowakowska 2011). Also interesting are the authors' observations that women who completed therapy compared to those who discontinued it had lower scores on the present-hedonism and past scales. This indicates that they are less likely to dwell on past events and focus on momentary pleasures. It is worth considering whether this is an effect of the therapy received, with a particular focus on working on alcohol craving, part of which is learning to cope with the compulsion for immediate gratification. It has been demonstrated, however, that participation in therapy can change time perspectives and orient towards the future, as was the case for heroin addicts who remained abstinent as opposed to active users of this drug (Alvos et al. 1993). Moreover, a future-oriented time perspective is a strong predictor of subjects' maintenance of abstinence after completing a drug rehabilitation programme (Lennings 1996). It also seems relevant to address the relationship between time perspective and the coping styles presented by psychoactive substance abusers. As research has shown, the more intense the future-oriented time perspective, the more often individuals choose action-focused coping strategies, while those scoring high on the present-oriented time perspective are more likely to use maladaptive strategies such as focusing on avoidance, wallowing in helplessness, or experiencing difficult feelings such as anger (Wills et al. 2001).

\section{Defence mechanisms and alcohol dependence}

It is pointed out that the strongest defence mechanism in the alcohol dependence is denial (Ward and Rothaus 1991). It is defined as follows: "it occurs in the form of denying the existence of one's own emotions, desires, thoughts, fantasies; it always impoverishes emotionally, causes general inhibition and hinders interpersonal relationships" (Grzesiuk 2005, p. 39). In the case of alcohol dependent individuals, it is understood as their (patients) unwillingness to admit their difficulties in reducing or stopping drinking and accepting the consequences of their alcoholic destruction. Patients do not confront the problem of their own alcohol abuse, using mechanisms such as: the already mentioned denial ("I am not sick, I drink like others"), rationalization ("I have to drink in order to do business or give a good reception to guests"), projection ("I drink because it is the fault of my demanding boss and resentful wife") or regression (Fox 1967). From the point of view of psychoanalysis, addiction is thus a consequence of a deeply rooted, self-destructive fixation on the oral stage of development (Cierpiałowska and Ziarko 2012). As demonstrated by the results of research, alcohol dependent individuals score higher than healthy ones when it comes to a group of defence mechanisms defined as "turning against oneself", i.e. coping with conflicting contents by directing destructive behaviours in one's own direction, e.g. masochism. Furthermore, addicts are characterised by higher levels of mechanisms belonging to the 'reversed' group, where individuals react in a neutral or positive way towards a frustrating object that arouse a negative effect, such as suppression or reactive formation, while they score lower than the control group when it comes to the cluster of mechanisms consisting in 'turning against the object', such as identification with the aggressor or displacement (Glaser and Ihilevich 1969).

Research has also shown that substance abusing patients have a higher prevalence of defence mechanisms such as pseudo altruism, schizoid fantasy, acting out and isolation. At the same time, the use of immature defence mechanisms correlates positively with the depth of addiction, antisocial behaviour and experience of early childhood trauma (Taskent et al. 2011). The alcohol dependent persons also score higher on the general neurotic 
mechanisms scale compared to the control group, but when it comes to the aggregate scores on the mature and immature mechanisms scales, it does not differentiate them from the control group (Evren et al. 2012). The authors noted that they scored higher only on some of the scales belonging to immature mechanisms - projection, acting out, splitting and somatisation (ibid.). A study conducted among a group of alcohol-dependent individuals who practice self-harm, and those who do not engage in such behaviour, showed that the former have a stronger manifestation of the acting out mechanism, while the latter group more often use sublimation, anticipation and suppression (Evren et al. 2012). Similar results were obtained in a group of female addicts here too, they scored higher on the acting out and schizoid fantasy scales than non-addicted respondents, and were less likely to use mechanisms such as sublimation, anticipation, dissociation or reactive formation (Bagheri et al. 2013). The above reports show that higher levels of mature defence mechanisms are associated with psychological well-being and better social functioning.

Based on the available literature, the following hypotheses were formulated:

1. There exist significant correlations between mature defence mechanisms (such as sublimation, humour, anticipation and suppression) and task-based coping style, and between emotional coping style and immature defence mechanisms (such as denial, displacement, acting out and devaluation) in patients with type I and type II alcohol dependence according to Lesch.

2. There exist significant correlations between task-focused style and future-oriented time perspective and avoidance-focused style and present hedonistic time perspective in patients with type I and II alcohol dependence according to Lesch.

\section{Description of the study group}

All individuals signed a written, voluntary and informed consent to participate in the study. The subjects were recruited from among the patients of the 24-hour Alcohol Dependence Treatment Unit (COTUA) and the Addiction Treatment Clinic in Lublin. The subjects met the criteria of Alcohol Dependence Syndrome and maintained at least 7 days of abstinence from alcohol. Exclusion criteria were the presence of active psychosis or alcoholic delirium and significant cognitive impairment preventing the completion of the questionnaire.

The patients ranged in age from 20 to 63 years, with a mean age of $37.86(\mathrm{SD}=20.87)$. A total of 73 patients with alcohol dependence - according to Lesch's typology - type I, and 28 with type II were distinguished. The remaining two groups were too small to be included in statistical calculations (type III $n=8$, type IV $n=3$ ).

\section{Research tools and methods}

The study was approved by the Bioethics Committee of the Medical University of Lublin (no. KE0254/191/2011). The diagnosis of alcohol dependence was established by a psychiatric specialist, according to the ICD-10 Classification of Mental and Behavioural Disorders, to assess the course of alcohol dependence, the Lesch's typology interview questionnaire was utilised. To measure coping styles, the Coping Inventory for Stressful Situations (CISS) by Endler and Parker (Endler and Parker, 1994) was used, in the Polish language adaptation by Strelau, Jaworowska, Szczepaniak and Wrześniewski (Strelau, et al. 2005). When examining the respondents' defence mechanisms, the Defence Mechanisms Questionnaire by Andrews, Singh, and Bond (Andrews et al. 1993) was utilised. Work on the Polish adaptation was conducted by Bogutyn, Pełczyński, Kokoszka and Holas (Bogutyn et al. 1999).

\section{Research results}

The results of the correlation between stress coping styles and defence mechanisms in subjects representing type I and II alcohol dependence according to Lesch are presented in Table 1. They showed that the higher the intensity of the task-focused coping style presented by the respondents, the higher the scores they obtained on 
the scale of humour and anticipation. In the described research, an average significant correlation was observed between the variable that is the style focused on emotions and defence mechanisms such as: passive aggression, isolation, devaluation, schizoid fantasy, denial and somatisation, as well as a statistically significant high correlation between the style focused on emotions and projection. The results of the study indicate that the more patients use a coping style focused on avoiding the problem, the more often they manifest defence mechanisms such as: anticipation, undoing, idealisation, projection, passive aggression and denial. In addition, respondents who more often choose social seeking as a coping style achieve higher scores on the following scales: idealization, projection, passive aggression, schizoid fantasies, denial, dissociation, and splitting. In the study, an average significant correlation was observed between the social contact seeking variable and anticipation $(0.25)$ and pseudo altruism (0.25). Correlation analysis also indicated weak negative correlations between the variables: social contact seeking and denial (-0.31), schizoid fantasy $(-0.28)$ and devaluation $(-0.27)$ among individuals with type I alcohol dependence according to Lesch.

Table 1. Correlation between stress coping styles and defence mechanisms in subjects representing type I and II alcohol dependence according to Lesch

\begin{tabular}{|c|c|c|c|c|c|c|c|c|c|c|}
\hline & \multicolumn{5}{|c|}{ I type acc. to Lesch } & \multicolumn{5}{|c|}{ II type acc. to Lesch } \\
\hline 1 & TO & EO & AO & A-D & A-S & TO & EO & AO & A-D & A-S \\
\hline Sublimation & n.s. & n.s. & n.s. & n.s. & n.s. & n.s. & n.s. & n.s. & n.s. & $0.45 *$ \\
\hline Humour & $0.25 *$ & n.s. & n.s. & n.s. & n.s. & n.s. & n.s. & n.s. & n.s. & n.s. \\
\hline Anticipation & $0.35 *$ & n.s. & $0.26 *$ & n.s. & $0.25 *$ & n.s. & n.s. & n.s. & n.s. & n.s. \\
\hline Suppression & n.s. & n.s. & n.s. & n.s. & n.s. & n.s. & n.s. & n.s. & n.s. & n.s. \\
\hline Undoing & n.s. & n.s. & $0.25 *$ & n.s. & n.s. & n.s. & n.s. & n.s. & n.s. & n.s. \\
\hline Pseudo altruism & n.s. & n.s. & n.s. & n.s. & $0.25 *$ & n.s. & n.s. & n.s. & n.s. & n.s. \\
\hline Idealisation & n.s. & n.s. & $0.36 * *$ & $0.31 *$ & n.s. & n.s. & n.s. & n.s. & n.s. & n.s. \\
\hline Reactive formation & n.s. & n.s. & n.s. & n.s. & n.s. & n.s. & n.s. & n.s. & n.s. & n.s. \\
\hline Projection & n.s. & $0.55 * * *$ & $0.33 * *$ & $0.43 * * *$ & n.s. & n.s. & n.s. & n.s. & n.s. & n.s. \\
\hline Passive aggression & n.s. & $0.49 * * *$ & $0.27 *$ & $0.42 * * *$ & n.s. & $-0.42 *$ & n.s. & n.s. & n.s. & n.s. \\
\hline Acting out & n.s. & n.s. & n.s. & n.s. & n.s. & n.s. & n.s. & n.s. & n.s. & n.s. \\
\hline Isolation & n.s. & $0.35 *$ & n.s. & n.s. & n.s. & n.s. & n.s. & n.s. & n.s. & n.s. \\
\hline Devaluation & n.s. & $0.35 *$ & n.s. & n.s. & $-0.27 *$ & n.s. & n.s. & n.s. & n.s. & n.s. \\
\hline Schizoid fantasy & n.s. & $0.47 * * *$ & n.s. & $0.36 * *$ & $-0.28 *$ & $-0.42 *$ & n.s. & n.s. & n.s. & n.s. \\
\hline Denial & n.s. & n.s. & n.s. & n.s. & $-0.31 \%$ & n.s. & n.s. & n.s. & n.s. & n.s. \\
\hline Repression & n.s. & $0.44 * * *$ & $0.27 *$ & $0.41 * *$ & n.s. & n.s. & n.s. & n.s. & n.s. & n.s. \\
\hline Dissociation & n.s. & n.s. & n.s. & $0.27 *$ & n.s. & n.s. & n.s. & n.s. & n.s. & n.s. \\
\hline Splitting & n.s. & n.s. & n.s. & $0.31 *$ & n.s. & n.s. & n.s. & n.s. & n.s. & n.s. \\
\hline Rationalisation & n.s. & n.s. & n.s. & n.s. & n.s. & n.s. & n.s. & n.s. & n.s. & n.s. \\
\hline Somatisation & n.s. & $0.39 * *$ & n.s. & n.s. & n.s. & n.s. & n.s. & n.s. & n.s. & n.s. \\
\hline
\end{tabular}

n.s. - not significant; TO - task-oriented style; EO - emotion-oriented style; AO -avoidance oriented style; A-D- avoidant-distracted; A-S - avoidant-social $* \mathrm{p}<0.05 ; * * \mathrm{p}<0.01 ; * * * \mathrm{p}<0.001$

The results of the correlation between stress coping styles and time perspectives in subjects representing type I and II alcohol dependence according to Lesch are presented in Table 2 . The correlation analysis indicated that among patients representing type I alcohol dependence according to Lesch, there is a statistically significant average relationship between the variable task-focused style and the future-oriented time perspective. The study also showed that the higher the score on the emotion-focused style scale achieved by the patients, the greater the tendency to orient towards the past, in a negative aspect. Moreover, a significant correlation was found at the average level between engaging in substitute activities and time perspective such as past negative $(\mathrm{r}=0.29)$ and present fatalistic $(\mathrm{r}=0.25)$. 
Table 2. Correlation between stress coping styles and time perspectives among respondents representing Type I and Type II alcohol dependence according to Lesch

\begin{tabular}{|c|c|c|c|c|c|c|c|c|c|c|}
\hline \multirow[b]{2}{*}{ ZTPI } & \multicolumn{5}{|c|}{ I type acc. to Lesch } & \multicolumn{5}{|c|}{ II type acc. to Lesch } \\
\hline & TO & EO & AO & A-D & $\mathbf{A}-\mathbf{S}$ & TO & EO & AO & A-D & A-S \\
\hline PN & n.s. & $0.35 *$ & n.s. & $0.29 *$ & n.s. & n.s. & $0.52 * *$ & n.s. & n.s. & n.s. \\
\hline $\mathbf{P P}$ & n.s. & n.s. & n.s. & n.s. & n.s. & n.s. & n.s. & $0.56 * *$ & $0.46 *$ & $0.37 *$ \\
\hline PF & n.s. & n.s. & n.s. & $0.25^{*}$ & n.s. & $-0.38 *$ & n.s. & n.s. & n.s. & n.s. \\
\hline PH & n.s. & n.s. & n.s. & n.s. & n.s. & n.s. & n.s. & n.s. & n.s. & n.s. \\
\hline Future & $0.43 * * *$ & n.s. & n.s. & n.s. & $0.43^{* * *}$ & n.s. & n.s. & n.s. & n.s. & n.s. \\
\hline
\end{tabular}

n.s. - not significant; TO - task-oriented style; EO - emotion-oriented style; AO -avoidance oriented style; A-D- avoidant-distracted; A-S - avoidant-social, $\mathrm{PN}$ - past negative; $\mathrm{PP}$ - past positive; $\mathrm{PF}$ - present fatalistic; $\mathrm{PH}$ - present hedonistic, $\mathrm{F}$ - future $* \mathrm{p}<0.05 ; * * \mathrm{p}<0.01 ; * * * \mathrm{p}<0.001$

The correlation analysis indicated that the higher the scores patients representing type II addiction according to Lesch achieved on the task-focused style scale, the lower was the intensity of the present fatalistic time perspective in them (Table 2). There is also a statistically significant correlation at a high level between the emotionfocused style and the past negative time perspective $(\mathrm{r}=0.52)$, as well as the avoidant coping style and the past positive time perspective $(\mathrm{r}=0.56)$. It was also demonstrated that the more frequently the respondents engaged in substitute activities as a coping style, the more they focused on the past, in its positive aspect. There is also a statistically significant positive relationship at the average level between social contact seeking and the past positive time perspective.

\section{Discussion of results}

The results obtained in this study partly confirmed the hypothesis assuming the existence of a relationship between mature defence mechanisms such as sublimation, humour, anticipation and suppression and task-based coping style, and between emotional coping style and immature defence mechanisms such as denial, repression, acting out and devaluation. Respondents with type I alcoholism according to Lesch, who present a taskbased coping style, exhibit a greater tendency to use mature defence mechanisms such as humour and anticipation (i.e. anticipating in advance difficulties that may arise and taking action to prevent this). These results seem to be in agreement with the findings of researchers (Endler and Parker 1994) who reported the occurrence of significant positive correlations between task-based coping style and mature defence mechanisms. According to Sala et al. (2015), higher levels of mature defence mechanisms are accompanied by more adaptive coping strategies such as positive reappraisal or creating a plan for further action. It is worth mentioning that mature defence mechanisms serve a protective function against the emergence of depressive symptoms and impulsive behaviour (Perry and Ianni 1998).

A significant inverse relationship between task-based coping style and immature defence mechanisms such as passive aggression and schizoid fantasies was found among patients belonging to type II alcohol dependence according to Lesch's classification. The more strongly these individuals focus on constructive problem solving when experiencing difficulties, the less inclined they are to close themselves off in their own world and wallow in fantasies, as well as to suppress their anger by displaying it in passive ways.

One may wonder why the correlation between task-based coping and mature coping mechanisms proved to be statistically significant only in patients with type I alcoholism according to Lesch, while among those with type II only an inverse correlation was observed between task-based coping and immature mechanisms. The results of studies show (Endler, Parker 1994) that the correlation indicating that more frequent use of task-based coping is accompanied by less frequent use of immature defence mechanisms is more prominent in the female group. Similarly, although this did not prove to be statistically significant, it is worth noting that among type II respondents according to Lesch in our study, nearly 40 per cent are female (compared to only 12 per cent in type I group). 
The differences in the correlation results obtained between coping styles and defence mechanisms in groups of patients with both type I and type II alcohol dependence according to Lesch may also be due to not taking into account variables that are potential mediators in this relationship. Gouvernet et al. (2014) indicate that such a role may be played by the subjects' perceived sense of control.

The results of our study have also shown that there is a positive relationship between seeking social contacts and mature defence mechanisms - suppression (among respondents with type I alcoholism according to Lesch) and sublimation (among those representing type II). This leads us to the assumption that, regardless of the type of addiction presented, of significance is leaning towards other people, establishing relationships with them and receiving support from them in the recovery process. This involves resolving internal conflicts in a manner that does not harm others and is creative and developmental for the respondents themselves. In this context, participation in self-help networks, AA in particular, appears to be important. It is worth citing the results of research showing that alcohol dependent individuals who attended meetings on average have four more people in their support network than those ones who do not engage in AA, and this support takes place on three levels: confiding, comforting and advising (Bronowski, 2000). The results obtained confirm that the initiation of o relationships during the sobering period favours the orientation of drive towards self-development. These interactions seem to be extremely valuable, as close family and friendship ties are often destroyed for addicts, and in recovery these roles are taken over by contacts with other community members.

The results of the study confirmed the assumption of a positive correlation between the emotional style of coping and immature mechanisms such as denial and devaluation among patients with type I alcoholism according to Lesch. The results obtained in the dissertation also report positive correlations on an average level between the emotional coping style and other immature coping mechanisms such as passive aggression, isolation, schizoid fantasy and somatisation. The results are consistent with the findings of Endler and Parker (1994), who highlight that the more individuals present a more intense emotional coping style, the more often they employ immature defence mechanisms, a correlation that applies to both the female and male groups. According to Sala et al. (2015), there is a positive relationship between the use of immature defence mechanisms and maladaptive coping strategies such as blaming others, catastrophizing or finding fault in oneself. Sammallahti et al. (2003), presented results showing that individuals using immature defence mechanisms have a lower sense of resourcefulness and meaningfulness, and find it more difficult to perceive stressful situations as challenges worth taking up. Research conducted on a group of addicts has also shown that the increased use of immature defence mechanisms is accompanied by excessive, destructive dependence in contacts with other people and making one's functioning and decisions dependent on the approval of others (Bornstein et al. 2010).

The only relationship the strength of which may be described as high is that between emotional coping and projection. Miller (1985) points out that alcohol dependent individuals are more likely than people in the healthy population to utilise this coping mechanism. This is confirmed by clinical practice, as addicted patients tend to focus on and analyse other people's alcohol problems, disregarding their own difficulties in this area. Research (Evren et al. 2012) has found that the use of immature defence mechanisms is associated with greater depth of addiction and experience of early childhood trauma. Alcohol dependent individuals who use immature defence mechanisms experience higher levels of anxiety and increased internal conflict, and are therefore more likely to use alcohol, which in turn leads to exacerbation of the disorder. Our research has demonstrated that in the group of people with type I alcohol dependence according to Lesch, where more correlations were found between emotional coping and immature defence mechanisms, the age of alcohol initiation was also significantly lower. Exploring the relationship between these variables appears to warrant further research, which, however, was not the purpose of this dissertation.

A result that stands in contrast to what has been assumed is the lack of connection between the emotional coping style and the defence mechanism of acting out, i.e. turning the feeling of helplessness into an experience of agency. Clinicians describe this mechanism as maladaptive, characterised by the fact that the person locates the source of his/her conflict outside (e.g. in another person or circumstances), and the frustration experienced as a 
result is difficult to bear and demands immediate outlet. Thus, patients who use acting out tend to behave impulsively and blame others for their predicament, which, to some extent, is also characteristic of individuals with an emotional coping style who tend to shift responsibility for their difficulties onto others (Perry, 2014). As Mc Williams points out "alcohol dependent individuals can be described as constantly playing out their relationship with the object of their addiction" (p.155). In a study by Evren et al. (2013), it was the severity of this defence mechanism that most differentiated the group of alcohol dependent patients who maintained abstinence after treatment from those who experienced relapse. The findings also failed to prove the existence of a relationship between emotional coping and denial.

Our research has also shown that among patients with type I alcohol dependence according to Lesch, positive correlations exist between the avoidant coping style and immature defence mechanisms, such as: projection, passive aggression and denial. These results partly correspond to the reports by Endler and Parker (1994) on the existence of a high positive correlation between avoidant coping style and the use of immature defence mechanisms, however, only in the female group. In our study, although it did not prove to be statistically significant, a higher percentage of patients with type II alcohol dependance according to Lesch were women (40\%) as compared to those with type I (12\%). A surprising result is the weak positive correlation between the mature defence mechanism of anticipation and avoidant coping.

In summary, the results obtained may become an important guideline for clinical practice, as withdrawal treatment personnel experience how their patients' defence mechanisms work in practice, during individual or group sessions. As highlighted by Di Giuseppe et al. (2014), the therapist's knowledge and understanding of the manifestations of the patient's defence mechanisms allows for a greater understanding of the material they bring to the sessions, as well as provides guidance when deciding when and how to interpret said defences.

Own research has shown that the more patients with type I alcohol dependence according to Lesch focus on understanding the situation and solving difficulties at the time of exposure to the stressor, the more often they focus on the future and making plans and creating visions for their future functioning. These results correspond with the reports of researchers showing that the more intense the future-oriented time perspective, the more often individuals choose action-focused coping strategies (Wills et al. 2001). The same authors have also found that a future-oriented perspective on time is a predictor of more adaptive, solution-focused coping strategies. Other studies have also shown that people with a task-focused coping style are better at anticipating the consequences of their actions, have greater impulse control, and are more likely to defer gratification, and these characteristics can be described as features of a future-oriented time perspective (Keough et al, 1999). The results of our research also revealed that the more strongly patients of type I according to Lesch focus on the task in moments of stress, the less frequently they manifest the present fatalistic time perspective, associated with experiencing a sense of hopelessness and lack of influence on reality.

Both in the group of patients with type I and type II alcohol dependence according to Lesch's classification, a more intensive use of the emotional style of coping was associated with focusing on the past time perspective in the negative aspect. This may be explained by the fact that people who concentrate on experienced anger or frustration in difficult situations are more likely to retrieve from memory events with negative emotional colouring. Referring to cognitive psychology, it should be emphasised that the memory process results in selective extraction of memories that are consistent with the mood. And vice versa, people who dwell on past painful events will have higher levels of sadness and discouragement. This is confirmed by van Beek et al.'s (2011) study that people with a negative past time perspective are more likely to experience depressive symptoms and suicidal thoughts. The results of a study conducted among people who experienced traumatic events such as sexual abuse, participation in armed struggles or fire, showed that those with a past negative time perspective, remain in a state of distress much longer than individuals focused on the future (Holman and Silver 1998). Looking at the past negative time perspective seems to be important as it appears to be the predictor of psychopathological symptoms, whereas focusing on negative interpretations of past events may be a bad predictor for the therapeutic process (van Beek et al., 2011). 


\section{Conclusions}

There exists a positive relationship between the avoidant coping style and the past positive time perspective. This relationship also applies to two forms of avoidant coping style - engaging in substitute activities and seeking social contacts, and was found to be statistically significant only in the group of patients with type II alcohol dependence according to Lesch. This may suggest that patients, when faced with a stressful situation, in order to avoid experiencing distress and pain, redirect their thoughts to pleasant past experiences. According to Zimbardo and Boyd (1999), the preference for a past positive time perspective may be related to a person's ease in using a support network. Other research has shown that "past positive" people are more likely to care for others, establish lasting relationships and communicate effectively (van Beek et al., 2011). Despite the numerous limitations of the study, such as the sample size, it may be a clue for therapeutic work with patients with various types of alcohol dependence according to Lesch.

\section{References}

Alvos, L., Gregson, R. A., Ross, M. W. (1993). Future time perspective in current and previous injecting drug users. Drug And Alcohol Dependence, 31(2), 193-197.

Anderson, P., \& Baumberg, B. (2006). Alkohol w Europie: perspektywa zdrowia publicznego Raport dla Komisji Europejskiej-Podsumowanie. Alkoholizm i Narkomania [Alcohol in Europe: a public health perspective Report to the European Commission-Summary. Alcoholism and Drug Addiction], 19(2), 121-137.

Andrews, G; Singh, M.; Bond M. (1993) The defence style questionnaire. The Journal of Nervous and Mental Disease, 181(4), 246-256.

Babor T. (1996). The classification of alcoholics: Typology theories from the 19th century to the present. Alcohol Health and Research World , 20(1), 6-17.

Bagheri, M., Azadfallah, P., Ashtiany, A. (2013). The comparison of defence and attachment styles in addicted/non-addicted women. Journal Of Psychology, 17(2), 220-236.

Bogutyn, T., Kokoszka, A., Palczynski, J., Holas, P. (1999). Defense mechanisms in alexithymia. Psychological reports, 84(1), $183-187$.

Bornstein, R. F., Gottdiener, W. H., Winarick, D. J. (2010). Construct Validity of the Relationship Profile Test: Links with Defense Style in Substance Abuse Patients and Comparison with Nonclinical Norms. Journal Of Psychopathology \& Behavioral Assessment, 32(3), 293-300.

Boyd, J. N., Zimbardo, P. G. (1997). Constructing Time After Death The Transcendental-Future Time Perspective. Time and Society, $6(1), 35-54$.

Bronowski, P. (2000). Wsparcie społeczne u członków wspólnoty Anonimowych Alkoholików. Alkoholizm i Narkomania [Social support in members of the Alcoholics Anonymous community. Alcoholism and drug addiction], 13(3), 337-346.

Cloninger CR. Neurogenetic adaptive mechanisms in alcoholism. Science 1987; 236: 410-416.

Cloninger CR, Sigvardsson S, Bohman M. Typ I i typ II alkoholizmu - uaktualnienie badan'. [Type I and type II alcoholism - a research update] In: Typologia alkoholizmu. Warszawa: PARPA; 2000. p. 50-64.

Cierpiałowska L., Ziarko M. (2012) Psychologia uzależnień - alkoholizm [Addiction psychology - alcoholism]. Warszawa, Oficyna Wydawnicza Łośgraf. ișpip

Chodkiewicz, J., Nowakowska K. (2011) Preferowana orientacja temporalna a przebieg leczenia odwykowego osób uzależnionych od alkoholu [Preferred temporal orientation and the course of alcohol withdrawal treatment], Psychiatria Polska, 65(2), 177-196.

Chodkiewicz, J., Nowakowska K. Orientacja temporalna a motywacja do leczenia odwykowego [Temporal orientation and motivation for addiction treatment], in: Leczenie alkoholików i członków ich rodzin. Perspektywa badawcza i praktyczna. [Treatment of alcoholics and their family members. Research and practice perspectives] Gąsior K., Chodkiewicz J., Kielce, Jedność, 2010

Di Giuseppe, M., Perry, J. C., Petraglia, J., Janzen, J., Lingiardi, V. (2014). Development of a Q-Sort Version of the Defense Mechanism Rating Scales (DMRS-Q) for Clinical Use. Journal Of Clinical Psychology, 70(5), 452-465.

Endler, N., Parker, J. (1994). Assessment of multidimensional coping: Task, emotion, and isép.javoidance strategies. Psychological Assessment, 6(1), 50 . 
Evren, C., Cagil, D., Ulku, M., Ozcetinkaya, S., Gokalp, P., Cetin, T., Yigiter, S. (2012). Relationship between defence styles, alexithymia, and personality in alcohol-dependent inpatients. Comprehensive psychiatry, 53(6), 860-867.

Fox, R. (1967). A multidisciplinary approach to the treatment of alcoholism. The American Journal of Psychiatry, 123(7), 769-778.

Gleser, G., Ihilevich, D. (1969). An objective instrument for measuring defence mechanisms. Journal Of Consulting And Clinical Psychology, 33(1), 51-60.

Grzesiuk, L. (2005). Psychoterapia Teoria. Podręcznik akademicki [Psychotherapy Theory. Academic textbook], 2.Warszawa, Wydawnictwo Eneteia.

Gouvernet B, Mouchard J, Combaluzier S. (2014) Path causal analysis of a model of a functional organization between defence mechanisms and coping strategies. L'encephale

Holman, E., Silver, R. (1998). Getting" stuck" in the past: temporal orientation and coping with trauma. Journal of personality and social psychology, 74(5), 1146.

Jellinek E.M. (1960). The disease concept of alcoholism. N.Brunswick: Hillh. Press.

Lesch, O., Dietzel, M., Musalek, M., Walter, H., Zeiler, K. (1998). The course of alcoholism. Long-term prognosis in different types. Forensic Science International, 36(1), 121-138.

Jakovljevic, M., Jovanovic, M., Rancic, N,, Vyssoki, B., Djordjevic, N. (2014) LAT Software Induced Savings on Medical Costs of Alcohol Addicts' Care - Results from a Matched-Pairs Case-Control Study. Plos One Journal, 9(11), 1-8.

Keough, K. A., Zimbardo, P. G., \& Boyd, J. N. (1999). Who's Smoking, Drinking, and Using Drugs? Time Perspective as a Predictor of Substance Use. Basic \& Applied Social Psychology, 21(2), 149-164.

Kiejna, A., Piotrowski, P., Adamowski, T., Moskalewicz, J., Wciórka, J., Stokwiszewski, J., Kessler, R. (2015).

Rozpowszechnienie wybranych zaburzeń psychicznych w populacji dorosłych Polaków z odniesieniem do płci i struktury wiekubadanie EZOP Polska [Prevalence of selected mental disorders in the adult Polish population with reference to gender and age structure - EZOP Poland survey]. Psychiatria Polska, 49(1), 15-27.

Klasyfikacja zaburzeń psychicznych i zaburzeń zachowania w ICD-10. Opisy kliniczne i wskazówki diagnostyczne [The ICD-10 classification of mental and behavioural disorders. Clinical descriptions and diagnostic guidelines]. Kraków-Warszawa: UWM „Vesalius”, IPiN; 1997, p. 69-79.

Kogoj, D., Lesch, O., Walter, H. (2010) Lesch Alcoholism Typology Medical Treatment and Research. Archives of Psychiatry and Psychotherapy, 12(4), 37-48.

Lesch OM, Walter H. Subtypes of alcoholism and their role in therapy. Alcohol Alcohol. 1996; supl. 1, $63-67$.

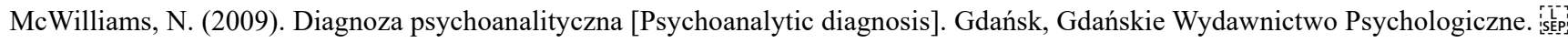
Miller, W. (1985). Motivation for treatment: A review with special emphasis on alcoholism. Psychological Bulletin, 98(1), 84-107.

Perry, J., Ianni, F. (1998). Observer-rated measures of defence mechanisms. Journal of Personality, 66, $993-1024$.

Petry, N., Bickel, W., Arnett, M. (1998). Shortened time horizons and insensitivity to future consequences in heroin addicts. Addiction, 93(5), 729-738.

Pombo, S., Lesch, O. (2009). The alcoholic phenotypes among different multidimensional typologies: similarities and their classification procedures. Alcohol and alcoholism, 44(1), 46-54.

Sala, M., Testa, S., Pons, F., Molina, P. (2015). Emotion regulation and defence mechanisms. Journal Of Individual Differences, 36(1), 19-29.

Sammallahti, P., Holi, M., Komulainen, E., Aalberg, V. (2003). Comparing two self-report measures of coping- the Sense of Coherence Scale and the Defense Style Questionnaire, Journal Of Clinical Psychology, 59(12), 1325-1333.

Samochowiec, A., Horodnicki, J. M., Samochowiec, J. (2011). Wpływ cech osobowości i polimorfizmów genów DRD4 i 5HTT rodziców na predyspozycje ich synów do uzależnienia się od alkoholu [Influence of parents' personality traits and DRD4 and 5HTT gene polymorphisms on their sons' predisposition to alcohol dependence]. Psychiatria Polska, 45(3), 337-347. 
Strelau, J., Jaworowska, A., Wrześniewski, K., Szczepaniak P. (2005). Kwestionariusz Radzenia Sobie w Sytuacjach Stresowych (CISS) [Questionnaire on Coping in Stressful Situations (CISS)] N.S. Endler, J.D.A. Parker - textbook, Warszawa, Pracownia Testów Psychologicznych.

Taskent, V., Karadag, F., Topcuoglu, V., Akduman, I., Evren, C. (2011). Psychological defence mechanisms, childhood traumas and dissociative experiences in patients with drug and alcohol dependency. Turk Psikiyatri Derg, 22, 58-64.

Wills, T., Sandy, J. M., Yaeger, A. M. (2001). Time perspective and early-onset substance use: A model based on stress-coping theory. Psychology Of Addictive Behaviors, 15(2), 118-125.

van Beek, W., Berghuis, H., Kerkhof, A., \& Beekman, A. (2011). Time perspective, personality and psychopathology: Zimbardo's time perspective inventory in psychiatry. Time \& society, 20(3), 364-3

Ward, L., Rothaus, P. (1991). The measurement of denial and rationalization in male alcoholics. Journal Of Clinical Psychology, 47(3), 465-468.

Woronowicz B. (2009) Uzależnienia. Geneza, terapia, powrót do zdrowia [Addictions. Genesis, therapy, recovery]. Warszawa, Parpamedia Publishing

Zawadzka, B., Byrczek, M. (2012). Kształtowanie perspektywy temporalnej jako aspekt adaptacji do choroby i leczenia. Analiza oparta na badaniach chorych leczonych narkozastępczo. [Temporal perspective formation as an aspect of adaptation to illness and treatment. An analysis based on studies of patients undergoing renal replacement therapy.], Psychiatria Polska, 46(5).

Zhang, J. W., Howell, R. T., \& Bowerman, T. (2013). Validating a brief measure of the Zimbardo Time Perspective Inventory. Time \& Society, 22(3), 391-409.

Zimbardo P., Boyd J. (2012) Paradoks czasu. [The Time Paradox] Warszawa, Wydawnictwo Naukowe PWN

Zimbardo, P. G., Boyd, J. N. (1999). Putting time in perspective: A valid, reliable individual - differences metric. Journal of personality and social psychology, 77(6), 1271

Katarzyna IWANICKA, psychologist, from 2020 to 2021 worked as associate professor at the Academy of Justice.

ORCID ID: https://orcid.org/0000-0001-5294-9021 